\title{
Nota sobre infinito atual e forma lógica no Tractatus
}

\author{
Bento Prado Neto
}

Professor da Universidade de São Carlos (UFSCar) 


\section{Nota sobre infinito atual e forma lógica no Tractatus}

Parece haver quase um consenso, entre os comentadores, em torno da tese segundo a qual o "primeiro Wittgenstein" nada veria de problemático na ideia de um infinito atual, ao contrário do que claramente ocorre com o "segundo Wittgenstein". O que eu gostaria de fazer aqui não é tentar reverter esse veredicto, mas sugerir que o exame das provas que o sustentam merece ser refeito. Para tanto, começarei por tentar mostrar como a letra dos aforismos 5.526 e 5.5262 parece levantar uma dificuldade para a tese consensual. Em seguida, procurarei encontrar, sob a letra, o espírito dessa dificuldade, isto é, buscarei nos princípios mais básicos do Tractatus as razões que subjazem às afirmações desses aforismos. Para finalizar, após fazer um balanço desse exame no que diz respeito à tese consensual, procurarei mostrar como ele aponta para a relevância da notação para o infinito, que João Vergílio Cuter prescreve para o Tractatus.

Palavras-chaves: Wittgenstein, Tractatus, infinito, forma lógica

\section{Note about actual infinity and logical form in Tractatus}

There seems to be almost a consensus among commentators regarding the thesis that 'the first Wittgenstein', in stark contrast with the second, saw no problem with the idea of an actual infinite. I do not seek to rebut this verdict here, but to suggest that the evidence offered for it needs to be re-considered. To this end, I begin by trying to show how aphorisms 5.526 and 5.5262, taken at face value, seem to raise a problem for the consensus thesis. Then, I will try to find the cause of this difficulty - to find among the principles of the Tractatus the reasons underlying the aphorisms' assertions. By way of conclusion, and having made a reckoning of the analysis of the consensus thesis, I will attempt to show that it points to the relevance of the notation for the infinite which João Vergílio Cuter prescribes for the Tractatus.

Key words: Wittgenstein, Tractatus, infinite, logical form 
P arece haver quase um consenso, entre os comentadores do Tractatus (Wittgenstein 4), em torno da tese segundo a qual Wittgenstein, na sua "primeira fase", nada veria de problemático na ideia de um infinito atual", ao contrário do que claramente ocorre na "segunda fase", desde seu primeiríssimo início, em 1929, quando a crítica dessa ideia se torna um dos alvos privilegiados da meditação wittgensteiniana. Esse diagnóstico quase consensual parece muito bem amparado tanto por provas de fato quanto por provas de direito, isto é, tanto por declarações explícitas de Wittgenstein a esse respeito quanto por certos princípios básicos de interpretação do Tractatus Logico-Philosophicus. As provas "de fato" incluem tanto aforismos do próprio Tractatus (como o aforismo 4.2211, no qual Wittgenstein admite expressis verbis a possibilidade de o mundo ser composto por infinitos estados de coisas, que consistiriam na concatenação de infinitos objetos simples) quanto declarações de Wittgenstein após 1929, nas quais ele aponta a admissão da possibilidade de um infinito atual como um dos erros fundamentais daquela sua primeira obra. A prova "de direito" resulta da leitura do grupo de aforismos 5.55, no qual se delineia um limite, por assim dizer, para as tarefas do Tractatus: a este caberia o que cabe à lógica, isto é, especificar "a forma geral da proposição", mas não aquilo que cabe à aplicação da lógica, isto é, a especificação da forma das proposições elementares, ou seja, em primeiro lugar, a especificação do "número dos nomes com significados diferentes" (Tractatus, 5.55). Dado esse corte entre a lógica e a aplicação da lógica, a posição do Tractatus só poderia ser de isenção com relação à infinidade ou não de objetos.

1 Isto é, no que irá nos interessar mais de perto, de uma infinidade de objetos. 
O que eu gostaria de fazer aqui não é tentar reverter esse veredicto, amplamente sancionado pelos comentadores, mas sugerir que o exame das provas que o sustentam merece ser refeito. Ainda que tal reexame não desemboque numa alteração da sentença final, ele me parece ser necessário para uma melhor compreensão das razões que (admitindo a correção do veredicto) levaram Wittgenstein a "mudar de opinião" acerca do infinito atual. Há certos problemas envolvidos na tese da isenção que costumam ser passados por alto quando se examina a passagem do primeiro para o segundo Wittgenstein. Problemas que, do ponto de vista do Tractatus, talvez se reduzam a uma sofisticação de uma exegese já garantida no essencial, mas que talvez sejam vitais para esclarecer as razões do abandono das teses tractarianas. Seguindo uma sugestão de João Vergílio Cuter, pode-se dizer que tais problemas gravitam em torno de uma tensão entre um aspecto "intensional” e um aspecto "extensional" do infinito no Tractatus: o primeiro vincula-se à concepção tractariana da matemática e suas relações com a lógica; o segundo vincula-se ao "contrapeso ontológico", por assim dizer, dessa concepção.

Na sua primeira obra, de fato, Wittgenstein contrapõe-se às versões fregiana e russelliana do logicismo, que adotam uma concepção "extensionalista" da matemática e fazem assim com que a infinitude dos números repouse sobre a existência de uma extensão infinita de conjuntos. Tornando as classes “desnecessárias na matemática”, Wittgenstein estaria, então, em condições de "dar conta" da matemática sem que lhe fosse preciso pronunciar-se sobre a existência ou não de infinitos objetos. Se o infinito na matemática se vê assim garantido sem a necessidade de recorrer a uma extensão infinita (como no Axiom of Infinity de Russell), por outro lado, a possibilidade (resultado da tese da isenção) da existência de infinitos objetos abre espaço para uma extensão infinita que traz exigências simbólicas que não se encontram imediatamente garantidas pelo tratamento "intensional” do infinito que estrutura a concepção tractariana da 
matemática. Essa tensão se revela, por exemplo, quando lembramos que um conjunto de infinitas proposições elementares determina uma quantidade não enumerável de funções de verdade diferentes (ou, em outras palavras, que uma tabela de verdade de uma função de verdade de infinitas proposições teria uma quantidade não enumerável de linhas): aqui, a infinitude não pode ser manejada, no plano simbólico, apenas "intensionalmente", e o símbolo teria de ser constituído por infinitas escolhas simbólicas independentes. Se aceitamos a possibilidade de infinitas proposições elementares, não há como recusar nenhuma das mais que infinitas possibilidades de atribuição de valores de verdade a elas.

Dada essa tensão, abrem-se duas possibilidades (excluindo a de simplesmente ignorar o problema): (i) considerar que a impossibilidade de constituir um símbolo infinito (algo como uma tabela de verdade infinita ou uma conjunção infinita) é uma limitação psicológica (algo "humanamente impossível"), e que, portanto, a restrição ao tratamento intensional do infinito só é logicamente relevante no que diz respeito à matemática; ou (ii) considerar que se trata efetivamente de uma impossibilidade lógica, isto é, considerar que a única maneira logicamente possível de simbolizar o infinito é por procedimentos intensionais. Nesse último caso, conviveriam no Tractatus a aceitação da possibilidade de uma infinidade atual (resultado da tese da isenção) e a recusa da possibilidade de sua simbolização (uma vez que não haveria como representar, por "meios estritamente intensionais" o resultado de uma infinidade de escolhas simbólicas independentes). Essa segunda alternativa tem portanto isto de problemático que ela põe em xeque o que parece ser um dos princípios mais fundamentais do Tractatus: ao negar a equivalência entre a possibilidade ontológica da existência de uma configuração aleatória de realizações de infinitos estados de coisas e a possibilidade lógica de sua simbolização, ela romperia a identidade entre o que pode ser e o que pode ser pensado, representado - haveria fatos possíveis, mas logicamente irrepresentáveis. Neste artigo, não vou levantar essa discussão (se é 
compatível com o Tractatus a admissão de uma possibilidade lógicoontológica que, por razões lógicas, não pode ser simbolizada); vou pressupor, como pano de fundo, essa identidade entre o que pode ser e o que pode ser pensado (ou representado).

Que essa tensão seja relevante para o exame da "mudança de posição" de Wittgenstein acerca do infinito é o que pode ser visto nas provas testemunhais que são arroladas pela tese da isenção, e que embaralham esses dois aspectos da infinitude. Algumas declarações claramente se referem a essa infinitude ontológica, e extensional (cuja possibilidade, e não realidade, é admitida pelo Tractatus segundo a tese da isenção): assim, por exemplo, o aforismo 4.2211 ou o aforismo 5.535. Mas outras parecem se referir a uma infinitude que dispensa qualquer referência a uma extensão infinita, uma infinitude propriamente intensional. Assim, Mathieu Marion (3, p. 34-35) cita, como provas da tese da isenção, tanto o aforismo 4.2211 quanto o 4.463. Ora, temos aqui duas "declarações" de teor fortemente diferente: a primeira se refere à possibilidade de um infinito atual, a segunda, à sua efetividade. Ora, a menos que tenha havido um lapso por parte de Wittgenstein, a infinitude do espaço lógico afirmada pelo aforismo 4.463 não pode se referir a uma infinidade de objetos ou de estados de coisas, pois, senão, violaria o princípio da isenção. Se Marion não comete o pecado de confundir essas duas questões (a infinitude do espaço lógico sugere uma infinitude que fluiria dos objetos e dos estados de coisas - e, assim, nada impede de ver nesse aforismo algo como um lapso por parte de Wittgenstein), ao não ressaltar essa distinção, ele acaba incluindo no conjunto das declarações sobre a infinitude extensional um comentário de Wittgenstein que talvez se refira à outra infinitude. Penso na alusão que ele faz à declaração posterior de Wittgenstein, ao seu aluno Desmond Lee, segundo a qual um dos erros do Tractatus teria sido o de "supor que possa haver um número infinito de proposições". De fato, a declaração não se refere a uma infinidade de objetos (nem de estados de coisas), mas de proposições, e podemos encontrar, no Tractatus, uma 
afirmação da existência de infinitas proposições, no aforismo 5.43, que explicitamente se refere ao campo da matemática - afirmação que, em perfeito acordo com a tese da isenção, está garantida independentemente da existência de infinitos objetos.

É claro que essa distinção entre a infinitude formal ou intensional e a infinitude extensional pode ser em parte esvaziada, se concebermos que a efetividade da primeira só é possível tendo como horizonte a possibilidade da segunda. Seguindo esse raciocínio, a admissão de uma infinidade "de proposições" equivaleria a admissão da possibilidade (embora não da efetividade) de uma infinidade de objetos. Mas, mesmo que haja tal nexo interno entre essas duas questões, elas devem ser distinguidas. Afinal, não é somente depois do Tractatus, mas também antes (isto é, não é somente a partir dos manuscritos de 1929, mas também nos Notebooks), que Wittgenstein parece ver problemas na admissão de uma infinidade de objetos. Em ambos os casos, embora por motivos diferentes, Wittgenstein está às voltas com aquilo que, segundo os aforismos 5.55, caberia à aplicação da lógica: em 1929 porque, num sentido ou noutro, é disso que se trata, isto é, dessa análise das proposições que deve revelar a forma das proposições elementares; nos Notebooks, porque a independência da lógica com relação à sua aplicação ainda não foi estabelecida.

Essas considerações muito gerais parecem-me mostrar que o exame dessa "tensão" seja relevante para a compreensão do abandono das teses do Tractatus acerca do infinito. O que irei fazer aqui, no entanto, é apenas explorar um aforismo do Tractatus no qual essa tensão parece vir à tona. Começarei, portanto, por tentar mostrar como a letra dos aforismos 5.526 e 5.5262 parece levantar uma dificuldade para a tese da isenção; em seguida, procurarei encontrar, sob a letra, o espírito dessa dificuldade, isto é, procurarei encontrar nos princípios mais básicos do Tractatus as razões que subjazem às afirmações desses aforismos; para finalizar, após fazer um balanço desse exame no que diz respeito à tese da isenção, procurarei mostrar 
como ele aponta para a relevância da notação para o infinito que João Vergílio Cuter prescreve para o Tractatus. ${ }^{2}$

O trecho que eu gostaria de comentar é composto por dois aforismos: o 5.526 e o 5.5262. Vou citá-los na íntegra, pois são bem curtos:

5.526 - Pode-se descrever integralmente o mundo por meio de proposições completamente generalizadas, ou seja, sem que nenhum nome seja de antemão coordenado a um objeto determinado.

Para se chegar, então, ao modo habitual de expressão, deve-se, após uma expressão: 'há um único $x$ tal que..., simplesmente dizer: e esse $x$ é $a$.

Que se possa descrever o mundo por meio de proposições completamente generalizadas, é uma trivialidade, dado o pano de fundo do Tractatus. ${ }^{3} \mathrm{O}$ que pode causar espanto ao leitor é, em primeiro lugar, a afirmação de que o mundo pode ser descrito integralmente desse modo. Esse termo - "integralmente" -, associado ao final desse aforismo, parece tornar essa descrição completamente generalizada equivalente - trata-se apenas de dois "modos de expressão", um "habitual", o outro não - a uma descrição completa do mundo. Tal identificação seria certamente problemática para a compreensão do estatuto e da função dos nomes simples; mas podemos deixar esse problema de lado, mesmo porque sempre se pode ler aquele "integralmente" numa acepção menos forte: Wittgenstein não estaria dizendo que por meio de proposições completamente generalizadas eu posso dizer tudo que pode ser dito, mas apenas que eu posso descrever, por meio delas, a totalidade do mundo (e não

2 Por exemplo, em Cuter 1, p. 109-140, ou em Cuter 2, p. 87-120.

3 O aforismo que iremos "pular", o 5.5261, é a retomada de uma observação dos Notebooks, que apresentava essa "trivialidade" como uma "descoberta". Se não comentamos esse aforismo intermediário, é porque iremos voltar a ele mais tarde. 
apenas uma parte); e isso ao preço de alguma perda - aquilo que vem a ser perdido nesse "modo de expressão" seria restituído quando, voltando ao "modo habitual de expressão", nós, por assim dizer, "damos nomes aos bois". A descrição integral do mundo por meio de proposições completamente generalizadas não ofereceria, então, uma descrição do mundo "sem resto", mas, para nos adiantarmos ao próximo aforismo a ser citado, descreveria apenas a "sua construção geral". Vamos, portanto, a ele:

5.5262 - A verdade ou falsidade de cada proposição altera, por certo, algo na construção geral do mundo. E o espaço de manobra que a totalidade das proposições elementares deixa para esta construção é precisamente aquele que as proposições inteiramente generalizadas delimitam.

(Se uma proposição elementar é verdadeira, é assim, de qualquer maneira, mais uma proposição elementar verdadeira).

O aforismo começa e termina evocando a importância de cada proposição elementar para a “construção geral do mundo", e é essa evocação que irá nos interessar; mas, antes, algumas palavras sobre essa "construção" ela própria, que é tematizada pelo "miolo" do aforismo. De imediato, parece razoável pensar que é essa "construção geral do mundo" que é descrita pelas proposições completamente generalizadas - isto é, que aquilo que é integralmente descrito, segundo o aforismo anterior, é essa “construção geral", e não o mundo, pura e simplesmente (a distância entre esses dois objetos de descrição - “o mundo", “a construção geral do mundo" — sendo marcada justamente pela reintrodução dos nomes próprios, que nos devolvem ao "modo habitual de expressão".

De fato, a totalidade das proposições elementares também "deixa um espaço de manobra" para o mundo (não para a sua "construção geral", isto é, não apenas para ela) e esse espaço de manobra é delimitado pelas proposições nãoelementares: dada a totalidade das proposições elementares, está dada a totalidade dos mundos possí- 
veis, cada um desses mundos correspondendo a uma distribuição de valores de verdade à totalidade das proposições elementares. Aqui, efetivamente, salta aos olhos que a verdade ou a falsidade de cada proposição elementar altera algo no mundo: leva-nos a um mundo diferente - mas não é de imediato claro que, ou por que, isso acarretaria uma alteração na "construção geral do mundo".

De fato, nas proposições completamente generalizadas, as constantes (os nomes) são substituídas por variáveis. Mas deve-se lembrar, aqui e para toda a discussão subsequente, que a notação proposta logo a seguir pelo Tractatus (nos aforismos 5.531 a 5.5321) impede que duas variáveis diferentes incidam sobre uma mesma constante (numa função de duas variáveis, estas não podem ser substituídas por uma única constante). Assim, tomemos dois mundos que diferissem entre si apenas porque tudo aquilo que no primeiro é verdadeiro acerca de determinado objeto - chamemo-lo "a" — no segundo é verdadeiro acerca de outro determinado objeto - chamemo-lo " $b$ "-, e vice-versa. Esses dois mundos seriam certamente diferentes, mas essa diferença por princípio não poderia ser capturada pelas proposições completamente generalizadas: seria esse o pequeno detalhe que lhes falta e que é suprido pela reintrodução dos nomes que nos leva ao "modo habitual de expressão". Teríamos, nesse caso, dois mundos distintos, mas uma única e mesma "construção geral". Em que, então, "a verdade ou falsidade de cada proposição altera algo na construção geral do mundo"?

O final do aforismo procura responder essa questão: "se uma proposição elementar é verdadeira, é assim de qualquer maneira mais uma proposição elementar verdadeira". Comparemos dois outros "mundos possíveis", que diferem entre si por apenas uma proposição elementar (e não, como no caso anterior, por dois blocos "simétricos", por assim dizer, de proposições). Nesse caso, não há duas alterações que podem "compensar uma à outra", a alteração estrutural que uma delas introduz neutralizando a alteração estrutural que a outra ia introduzindo. Essa alteração, portanto, que modifica o valor de verdade de apenas uma proposição elementar, poderia, segundo 
o aforismo, ser capturada pelas proposições completamente generalizadas: na descrição de um dos mundos, por exemplo, à proposição $\mathrm{Fa}$, verdadeira nesse mundo, corresponderia a proposição $(\mathrm{Ef}, \mathrm{x}) \mathrm{fx}$, sua forma completamente generalizada, ao passo que na descrição do outro mundo, no qual $\sim \mathrm{Fa}$, eu teria $(\mathrm{Ef}, \mathrm{x}) \sim \mathrm{fx}$ correspondendo ao fato de que $\sim \mathrm{Fa}$. A ideia seria, portanto, que a verdade ou a falsidade de cada proposição elementar traz uma contribuição para a construção geral do mundo, ou seja, encontra alguma expressão nas proposições completamente generalizadas. $\mathrm{E}$ isso sem negar que mundos diferentes possam ter a mesma construção geral, uma alteração estrutural podendo ser anulada por outra. Chegamos, agora, ao ponto que nos interessa.

Se eu tenho um número finito de nomes diferentes de mesma forma lógica que podem satisfazer a uma mesma função proposicional, é fácil ver como a alteração do valor de verdade é captada pelas proposições completamente generalizadas. Por exemplo, se num mundo eu tenho $F a, F b$ e $F c$ verdadeiras, mas $F d$ e $F e$ falsas (e nenhum outro nome que possa entrar no lugar de $a, b, c, d$ e $e$ ), posso descrevê-lo assim (lembrando a peculiaridade da notação do Tractatus acima evocada, e deixando de lado a questão relativa à especificação da função $F$, assim como o seu estatuto $\left.{ }^{4}\right)$ :

$(\mathrm{Ef}, \mathrm{x}, \mathrm{y}, \mathrm{z}) \mathrm{fx} \& \mathrm{fy} \& \mathrm{fz} \&(\sim \mathrm{Ef}, \mathrm{x}, \mathrm{y}, \mathrm{z}, \mathrm{w}) \mathrm{fx} \& \mathrm{fy} \& \mathrm{fz} \& \mathrm{fw}$.

Mudando o valor de verdade de apenas uma daquelas proposições elementares, muda a descrição "geral" do mundo, seja para

(a) $(E f, x, y, z, w) f x \& f y \& f z \& f w \&(\sim E f, x, y, z, w, m) f x \& f y \& f z \& f w \& f m$, ou para

(b) $(\mathrm{Ef}, \mathrm{x}, \mathrm{y}) \mathrm{fx} \& \mathrm{fy} \&(\sim \mathrm{Ef}, \mathrm{x}, \mathrm{y}, \mathrm{z}) \mathrm{fx} \& \mathrm{fy} \& \mathrm{fz}$.

4 Isso equivale a tomar o problema num passo anterior ao da generalização completa, isto é, no momento em que eu já substituí as constantes $a, b, c$ etc., mas não a constante $F$. Seria possível, portanto, reescrever as fórmulas que seguem do seguinte modo: $(E x, y, z)$ Fx\&Fy\&Fz\&( $(\mathrm{Ex}, \mathrm{y}, \mathrm{z}, \mathrm{w})$ Fx\&Fy\&Fz\&Fw. O problema que iremos tentar descrever põe-se já nesse primeiro estágio de generalização, e não parece poder se dissolver nas etapas subsequentes. 
Mas, e se eu tiver um número infinito de nomes diferentes de mesma forma lógica? Ainda assim, a alteração do valor de verdade de uma proposição elementar pode ser captada por proposições completamente generalizadas em certos casos: basta que os nomes que satisfazem a essa função sejam em número finito, ou então que aqueles que não satisfazem o sejam. Teríamos, então (escolhendo "dois" como o "número finito"), respectivamente:

(a) $(E f, x, y) f x \& f y \&(\sim E f, x, y, z) f x \& f y \& f z$

ou

(b) (Ef,x,y) fx\& fy \&( $(\mathrm{Ef}, \mathrm{x}, \mathrm{y}, \mathrm{z}) \sim \mathrm{fx} \& \sim \mathrm{fy} \& \sim \mathrm{fz}$

como proposições completamente generalizadas caracterizando o mundo. Em ambos os casos, a alteração do valor de verdade de uma única proposição elementar levaria a proposições completamente generalizadas diferentes, pois se essa alteração consistisse, por exemplo, em que uma proposição $F a$ (ou $\sim F a$, respectivamente) que era verdadeira nesse mundo seja falsa no outro, teríamos respectivamente as seguintes proposições:

(a') (Ef,x)fx\&( $\sim E f, x, y) f x \& f y$ ou

(b') $(\mathrm{Ef}, \mathrm{x}) \sim \mathrm{fx} \&(\sim \mathrm{Ef}, \mathrm{x}, \mathrm{y}) \sim \mathrm{fx} \& \sim \mathrm{fy}$.

Nesses casos, portanto, não aparece nenhum problema. Uma proposição verdadeira "a mais" altera algo na construção geral do mundo, alteração que é captada pelas proposições completamente generalizadas. Mas, se há infinitos objetos que podem satisfazer essa função, não há o que possa proibir que outro caso ocorra: que infinitos desses nomes satisfaçam essa função e que outros também infinitos nomes não satisfaçam essa função. De fato, vejamos.

Não importa muito como eu devo expressar esse fato (o fato de que infinitos nomes satisfazem e infinitos não satisfazem uma função proposicional); voltaremos, adiante, à questão do modo como devemos expressar proposições desse tipo. Mas, se eu tenho uma proposição completamente generalizada descrevendo esse mundo, a alteração do valor de verdade de uma das proposições atômicas não irá provocar nenhuma alteração na "construção geral do mundo" que 
é captada por essa proposição. Dado um mundo 1, no qual infinitas proposições $F x$ são verdadeiras e infinitas proposições $F x$ são falsas, e um mundo 2 que só diferisse do primeiro pelo fato de que uma proposição elementar $\mathrm{Fa}$ é verdadeira nele mas falsa no primeiro, um tal mundo, que segundo o aforismo deveria diferir estruturalmente do outro, continua sendo descrito pelas mesmas proposições completamente generalizadas. Seja lá como for que devamos formular tais proposições, quando eu passo do "modo habitual de expressão", com constantes, para proposições completamente generalizadas ou, mais simplesmente, quando eu introduzo um quantificador - a minha representação só capta a diferença numérica entre os objetos. Não me parece casual que o aforismo que estamos discutindo seja seguido pelo 5.53: "Exprimo a igualdade do objeto por meio da igualdade do sinal e não com a ajuda de um símbolo de igualdade. A diferença dos objetos, por meio da diferença dos sinais". E é justamente essa diferença numérica que é apagada no reino do infinito: infinito e "infinito mais um" dá no mesmo. No reino do infinito, uma proposição elementar verdadeira a mais não é mais uma proposição elementar verdadeira, e a alteração que ela introduz no mundo se restringe ao fato de que é esta proposição que, antes falsa, agora é verdadeira - e é justamente esse "esta" que é suprimido pela substituição de constantes por variáveis.

E essa dificuldade não parece ser uma dificuldade na qual talvez Wittgenstein "não tenha pensado": de que outra maneira ler a insistência de Wittgenstein nesse "uma proposição mais"?

Se pudermos considerar estabelecida a dificuldade que o aforismo comentado apresenta para a ideia de que o Tractatus abre a possibilidade de um mundo constituído por infinitos objetos, cabe examinar duas questões, relativas ao sentido dessa dificuldade. O que procuramos mostrar na seção precedente é que a dificuldade resulta da 
combinação de duas teses, presentes no aforismo em questão: (i) é possível especificar a "estrutura geral do mundo" por meio de proposições completamente generalizadas; (ii) "a verdade de uma proposição elementar a mais altera a estrutura geral do mundo". Ora, o que cabe é tentar compreender o que, na estrutura do Tractatus, fundamenta cada uma dessas teses.

Com relação à primeira, a resposta parece clara. De fato, o aforismo 3.315 do Tractatus nos oferece uma caracterização do resultado da transformação de todas as constantes de uma proposição em variáveis (resultado que, justamente, é "quase" uma proposição completamente generalizada, faltando apenas a introdução dos quantificadores existenciais no início do símbolo obtido): o que assim se obtém é a forma lógica da proposição. Na proposição, podemos distinguir forma e conteúdo; quando pomos toda menção ao conteúdo de lado - quando eliminamos todas as constantes -, ficamos apenas com a forma. Assim, podemos dizer que à descrição "completa" do mundo por meio de proposições completamente generalizadas corresponde a forma lógica da descrição completa do mundo. Portanto, a tese que afirma ser possível especificar a "estrutura geral do mundo" por meio de proposições completamente generalizadas apoia-se no conceito de forma lógica: negar a possibilidade daquela descrição equivaleria a negar a forma lógica de uma descrição completa do mundo.

E a segunda tese? Assumindo como correta a leitura da primeira tese, que acabamos de apresentar, a questão torna-se esta: por que, exatamente, a verdade ou a falsidade de cada proposição elementar altera algo na forma lógica da descrição do mundo? Como vimos, essa tese obviamente não significa que toda alteração dos valores de verdade de proposições resulte numa alteração estrutural (que diferentes descrições do mundo não possam compartilhar uma mesma forma lógica). Ela significa que a cada proposição, elementar ou não (desde que possua condições de verdade, isto é, desde que não seja nem uma tautologia nem uma contradição), corresponde uma 
contribuição específica para a estrutura geral da descrição - para a forma lógica dessa descrição. Assim, parece que a segunda tese pode ser derivada da tese tractariana da independência lógica entre as proposições elementares. Cada proposição elementar, sendo logicamente independente das outras, traz uma contribuição também independente para a forma lógica da descrição total.

O que concluir disso? Não exatamente que esse aforismo nega, implicitamente (eppur si muove), a possibilidade de uma infinidade de objetos: o máximo que se poderia extrair imediatamente dele é que ele se opõe à possibilidade de uma infinidade de objetos de mesma forma lógica. Se os infinitos objetos têm (ou puderem ter) cada um deles uma forma lógica diferente, o raciocínio não se põe, pois eles não seriam diferenciados "meramente por serem diferentes", sua diferença não seria meramente numérica, mas formal, e não seria apagada, mas antes realçada, no momento em que substituíssemos constantes por variáveis. Ora, essa conclusão é embaraçosa para ambos os partidos: tanto para quem sustenta a tese, aparentemente mais razoável, de uma imparcialidade do Tractatus com relação à existência ou não de infinitos objetos, quanto para aqueles que namoram a ideia heterodoxa de uma posição mais radicalmente finitista da primeira obra de Wittgenstein. A conclusão é embaraçosa para os primeiros porque, embora esse problema só ataque "localmente" (só no campo dos objetos de mesma forma lógica) a possibilidade de uma infinidade de objetos, ele a ataca, por assim dizer, no seu local privilegiado: levando a sério essa dificuldade, fica ainda aberto um campo para uma infinidade de objetos, mas um campo atrelado a uma infinidade de formas lógicas diferentes e dadas (não construídas). Mas essa conclusão é de natureza a embaraçar também os segundos, não apenas porque seu alvo não foi completamente conquistado (uma 
aldeia permanece irredutível...), mas também porque introduz uma assimetria no problema do infinito que parece exigir explicações.

Resta que esse problema sugere a relevância da proposta de Ramsey e de João Vergílio ${ }^{5}$ para a notação do infinito. De fato, lembremos, rapidamente em que consiste essa proposta. Para que eu diga que há infinitos xs que são $F$ s, eu precisaria primeiro construir a série formal das proposições que asseveram que há um número finito de $x$ s que são $F$ s:

$$
\begin{aligned}
& \left(w^{1}\right) \sim(\mathrm{Ex}) \mathrm{Fx} \\
& \left(w^{2}\right)(\mathrm{Ex}) \mathrm{Fx} \&(\sim \mathrm{Ex}, \mathrm{y}) \mathrm{Fx} \& \mathrm{Fy} \\
& \left(w^{3}\right)(\mathrm{Ex}, \mathrm{y}) \mathrm{Fx} \& \mathrm{Fy} \&(\sim \mathrm{Ex}, \mathrm{y}, \mathrm{z}) \mathrm{Fx} \& \mathrm{Fy} \& \mathrm{Fz}
\end{aligned}
$$

Depois, eu nego a totalidade das proposições selecionadas por essa série: $\mathrm{N}(w)$. Por que esse desvio? Por que não dizer diretamente: (Ex,y,z...ad inf)Fx\&Fy\&Fz...ad inf? As razões que impedem essa formulação da proposição, ao que me parece, não devem ou não precisam ser encontradas nem numa "limitação de nossas capacidades humanas", que não conseguiriam abarcar um símbolo infinito (afinal, ela não é limitada para abarcar um "espaço lógico infinito" ou uma totalidade infinita de nomes simples), nem na impossibilidade de uma "lista" infinita de símbolos. O problema me parece residir no fato de que, ao contrário do que ocorre no caso finito, tal símbolo ((Ex,y,z...ad inf)Fx\&Fy\&Fz...ad inf) não seria propriamente complexo ou, pelo menos, não teria a complexidade que aparenta ter. De fato, como vimos em nosso comentário do aforismo 5.5262, esse símbolo não difere do símbolo (Ey,z...ad inf) Fy\&Fz...

5 Proposta com um sentido diferente em cada um dos casos: João Vergílio Cuter a propõe como uma consequência do Tractatus; já Ramsey, que desde o início se opunha a certas teses tractarianas, a introduz num momento em que o próprio Wittgenstein já se afastara substancialmente do Tractatus (e, portanto, o fato de ele criticar essa ideia não depõe imediatamente contra a tese de João Vergílio Cuter).. 
ad inf, no qual "retiramos" uma variável, nem do símbolo (Et,x,y,z... ad inf)Ft\&Fx\&Fy\&Fz...ad inf), no qual "acrescentamos" uma. Isto é: suas "partes" aparentes não são constituintes independentes de cuja combinação resulta o símbolo (eu posso retirá-las e acrescentá-las à vontade, sem alterar o símbolo) e, portanto, não "mantêm independentemente relações designativas com o mundo", como preconizava o aforismo 5.5261, justamente o aforismo que havíamos "pulado" em nosso comentário.

\section{Referências bibliográficas}

1. Cuter, J. V. “A aritmética do Tractatus”. In: Manuscrito, XVIII, 2, 1995.

2.

3. MARION, M. Wittgenstein, finitism and the foundations of mathematics. Oxford: Oxford University Press, 1998.

4. Wittgenstein, L. Tractatus logico-philosophicus. Trad. L. H. Lopes dos Santos. São Paulo: Edusp, 1994. 
